\title{
Specification of APS Corrector Magnet Power Supplies from Closed Orbit Feedback Considerations.
}

\author{
L. Emery and G. Decker
}

August 6, 1991

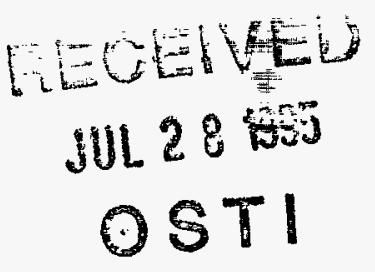

\section{Goal}

To specify or confirm the strengths and resolutions of the corrector magnets and their power supplies.

The photon beam must be stable to $5 \%$ of the phase space dimensions of the beam ( $10 \%$ of the emittance). Specification of the closed-orbit displacement in the insertion device appears in the CDR, page II.1-42:

$$
\begin{array}{r}
\Delta \sigma_{x}<16 \mu \mathrm{m} ; \quad \Delta \sigma_{x^{\prime}}<1.2 \mu \mathrm{rad} ; \\
\Delta \sigma_{y}<4.4 \mu \mathrm{m} ; \quad \Delta \sigma_{y^{\prime}}<0.45 \mu \mathrm{rad} ;
\end{array}
$$

Global and local correction systems will remove DC and oscillatory components of the orbit distortion. The oscillatory orbit distortion is usually attributed to the ground motion coupling to the quadrupole supports, but one should not assume that ground motion is the unique source.

\section{Formulae, Design Handbook Data, and Assumptions Used}

The deflection angle of a corrector magnet is related to the magnetic field by

$$
\theta[\mathrm{rad}]=0.3 \frac{B[\mathrm{~T}] L_{\mathrm{eff}}[\mathrm{m}]}{E[\mathrm{GeV}]}
$$

The impedance $Z$ of a magnet is given by

$$
Z=R+i 2 \pi f L
$$

where $R$ is the resistance and $L$ is the inductance which could be substantial compared to $R$ at the frequencies concerned. The cutoff frequency,

$$
f_{\mathrm{c}}=\frac{R}{2 \pi L}
$$

is defined as the frequency at which the magnitude of the impedance is twice the value of $R$. The lower the value of $f_{c}$ listed in Table 1 the larger role the magnet inductance will play in determining the power supply voltage specification.

The data on corrector magnets and power supplies shown in Table 1 appears in the Design Handbook. The sextupole dipole coils are used for vertical steering. The power supply voltage specification assumes a $50 \%$ chopping duty cycle. The corrector power supplies can be run as high as about $90 \%$ duty cycle, generating a voltage as high as twice the magnet DC $I R$ drop. 


\section{DISCLAIMER}

Portions of this document may be illegible in electronic image products. Images are produced from the best available original document. 
Table 1: Design Handbook Magnet and Power Supply Data

\begin{tabular}{|l|c|c|c|c|}
\hline Magnet & $\begin{array}{c}\text { Horizontal } \\
\text { Correction }\end{array}$ & $\begin{array}{c}\text { Sextupole } \\
\text { Dipole Coils }\end{array}$ & $\begin{array}{c}\text { Horizontal } \\
\text { H/V Combination }\end{array}$ & $\begin{array}{c}\text { Vertical } \\
\text { H/V Combination }\end{array}$ \\
\hline Max. field T & .23 & .11 & .16 & .16 \\
\hline$L_{\text {eff }}(\mathrm{m})$ & .14 & .28 & .20 & .20 \\
\hline $\begin{array}{l}\text { Max. DC deflection } \\
\text { at } 7 \mathrm{GeV} \theta_{\mathrm{DC}}(\mathrm{mrad})\end{array}$ & 1.3 & 1.2 & 1.2 & 1.2 \\
\hline Max. current $I(\mathrm{~A})$ & 89 & 113 & 116 & 134 \\
\hline$\theta / I[\mu \mathrm{rad} / \mathrm{A}]$ & 14.6 & 10.6 & 11.4 & 9.8 \\
\hline Impedance $(\mathrm{m} \Omega)$ & $127+77 f$ & $187+54 f$ & $133+25 f$ & $95+19 f$ \\
\hline$f_{\mathrm{c}}(\mathrm{Hz})$ & 1.6 & 3.4 & 5.3 & 5.0 \\
\hline Impedance at DC $(\Omega)$ & 0.127 & 0.187 & 0.133 & 0.095 \\
\hline Impedance at 25 Hz $(\Omega)$ & 2.05 & 1.54 & 0.76 & 0.57 \\
\hline Max. voltage at DC $(\mathrm{V})$ & 11.4 & 21.1 & 15.4 & 12.7 \\
\hline Power Supply Specification $(\mathrm{V})$ & 13 & 23 & 17 & 14 \\
\hline$\theta_{\mathrm{DC}} / V_{\mathrm{DC}}[\mu \mathrm{rad} / \mathrm{V}]$ & 114 & 57 & 86 & 103 \\
\hline
\end{tabular}

The eddy current attenuation of the magnetic field through the vacuum chamber is shown in table 2. The attenuation depends on the vacuum chamber thickness, the shape of the vacuum chamber, and the configuration of the magnetic poles. The attenuation of the vacuum chamber for the dipole field produced by the $\mathrm{H} / \mathrm{V}$ combination magnet was not measured. We know, however, that the thickness of the $\mathrm{H} / \mathrm{V}$ magnet elliptical vacuum chamber is half that of the regular vacuum chamber. The attenuation is going to be less for these dipoles than for the others.

\section{Global vs Local and DC vs AC Orbit Corrections}

One can divide the orbit correction into four systems:

1. Global correction at DC

2. Global correction up to $25 \mathrm{~Hz}$

3. Local correction at DC

4. Local correction up to $25 \mathrm{~Hz}$

Each use different position monitors and different sets of corrector magnets. Table 3 lists parameters for the above correction systems.

\subsection{Global Correction at DC}

The DC global correction will be used to correct the orbit of a stored beam. The DC orbit at the photon sources must be set to within the resolution of the RF beam position monitors (BPMs) located there. The Design Handbook-specified resolution for the RF BPMs is $25 \mu \mathrm{m}$, but $5 \mu \mathrm{m}$ 
Table 2: Eddy Current Attenuation for Magnet/vacuum Chamber Systems

\begin{tabular}{|c|c|c|c|c|}
\hline $\begin{array}{c}\text { Frequency } \\
(\mathrm{Hz})\end{array}$ & $\begin{array}{c}\text { Horizontal } \\
\text { Correction }^{*}\end{array}$ & $\begin{array}{c}\text { Sextupole } \\
\text { Dipole Coils** }\end{array}$ & $\begin{array}{c}\text { Horizontal } \\
\text { H/V Combination }\end{array}$ & $\begin{array}{c}\text { Vertical } \\
\text { H/V Combination }\end{array}$ \\
\hline .1 & 1.0 & 1.0 & 1.0 & 1.0 \\
1 & 0.96 & & & \\
5 & 0.67 & 0.97 & & \\
10 & 0.38 & 0.89 & & \\
15 & 0.32 & & & \\
20 & 0.20 & 0.69 & & \\
25 & 0.15 & 0.61 & & \\
\hline
\end{tabular}

* Measured by Y. Chung

** Calculated by L. Kettunen

Table 3: Specification of Correction Systems

\begin{tabular}{|l|c|c|c|c|}
\hline & Global DC & Local DC & Global 25 Hz & Local 25 $\mathrm{Hz}$ \\
\hline $\begin{array}{l}\text { Orbit measurement } \\
\text { device }\end{array}$ & $\begin{array}{c}\text { All of the } \\
\text { RF BPMs }\end{array}$ & $\begin{array}{c}\text { X-ray } \\
\text { BPMs }\end{array}$ & $\begin{array}{c}\text { RF BPMs at } \\
\text { sources only }\end{array}$ & $\begin{array}{c}\text { X-ray } \\
\text { BPMs }\end{array}$ \\
\hline Correctors & All correctors & Local bump & Subset of correctors & Local bump \\
\hline $\begin{array}{l}\text { Specified orbit } \\
\text { measurement resolution }\end{array}$ & $25 \mu \mathrm{m}$ & Not specified & $25 \mu \mathrm{m}$ & Not specified \\
\hline Achievable resolution & $5 \mu \mathrm{m}$ & $1 \mu \mathrm{m}$ & $5 \mu \mathrm{m}$ & $1 \mu \mathrm{m}$ \\
\hline $\begin{array}{l}\text { Required range of } \\
\text { orbit correction }\end{array}$ & $\pm 20 \mathrm{~mm}$ & $\pm 100 \mu \mathrm{m}$ & $\pm 500 \mu \mathrm{m}$ & $\pm 100 \mu \mathrm{m}$ \\
\hline
\end{tabular}


is achievable. For the undulator an RF BPM will be installed on the small cross-section vacuum chamber. The resolution there will be better by approximately a factor of four in both planes. Since the time interval between corrections is relatively long, one can use all of the RF BPMs amd correctors for the correction.

Because the resolution of the RF BPMs used in the global correction is $25 \mu \mathrm{m}$, the smallest orbit displacement achievable is $25 \mu \mathrm{m}$. In order to comply with the CDR specification in equation (1) a local orbit distortion is planned.

\subsection{Local correction at DC}

For the local correction, the orbit at the photon sources are measured by X-ray BPMs with a position resolution of $1 \mu \mathrm{m}$ and an angular resolution of $0.1 \mu \mathrm{rad}$. The position and angle coordinate of the orbit are controlled by a set of four correctors. Figures 1 and 2 show the position of the correctors producing the local orbit distortion for both types of photon source. $\mathrm{CH}$ and $\mathrm{CV}$ are horizontal and vertical correctors, respectively.

Dynamic range Because the X-ray BPMs have better resolution than RF BPMs, the DC local correction can steer the orbit closer to the design orbit. In order for the local correction system to work, the dynamic ranges of both the global and local systems must overlap. This means that the range of the local correction should exceed the resolution of the RF BPMs used in the global correction. With a safety factor of 4 in the overlap, we take the required dynamic range of the DC local correction to be $\pm 100 \mu \mathrm{m}$.

This number is reasonable from the point of view of the global feedback system designer. Global stability significantly better than $100 \mu \mathrm{m}$ could be difficult to achieve. In addition, the correction magnets may be required to run with a $\mathrm{DC}$ offset, reducing the effective dynamic range. Furthermore, it may be desirable to use the same magnet for two or more feedback systems which would require greater dynamic range.

\subsection{AC Global Correction}

If the amplitude of oscillatory orbit motion is very large - especially because of amplification due to the lattice focusing - a global correction system is necessary to correct the orbit. Because of time delays in communicating the orbit information, the number of RF BPMs used is limited. For the same reason, only a subset of correctors is used. In general distributed correctors can correct the orbit more efficiently than local bumps, and much larger orbit motions can be controlled.

The range of orbit correction is specified somewhat arbitrarily at $500 \mu \mathrm{m}$. Although calculations based on a few ground motion surveys indicate that the beam motion at frequencies up to $25 \mathrm{~Hz}$ is already within the tolerances defined by the CDR without feedback, the feedback system must be capable of correcting even larger orbit motions from sources other than ground motion.

\subsection{AC Local correction}

This uses the same hardware system as the DC local correction. The special consideration is that, at high frequencies, the magnetic field is strongly attenuated by the vacuum chamber (Table 2), and the inductance in some of the magnets (Table 1) causes a 15-fold increase in their impedances.

Dynamic range The same argument is made for local correction at AC as was put forth for the local correction at $\mathrm{DC}$. The required range of the local correction is therefore set at $\pm 100 \mu \mathrm{m}$. 
Figure 1: Local correction at an undulator section

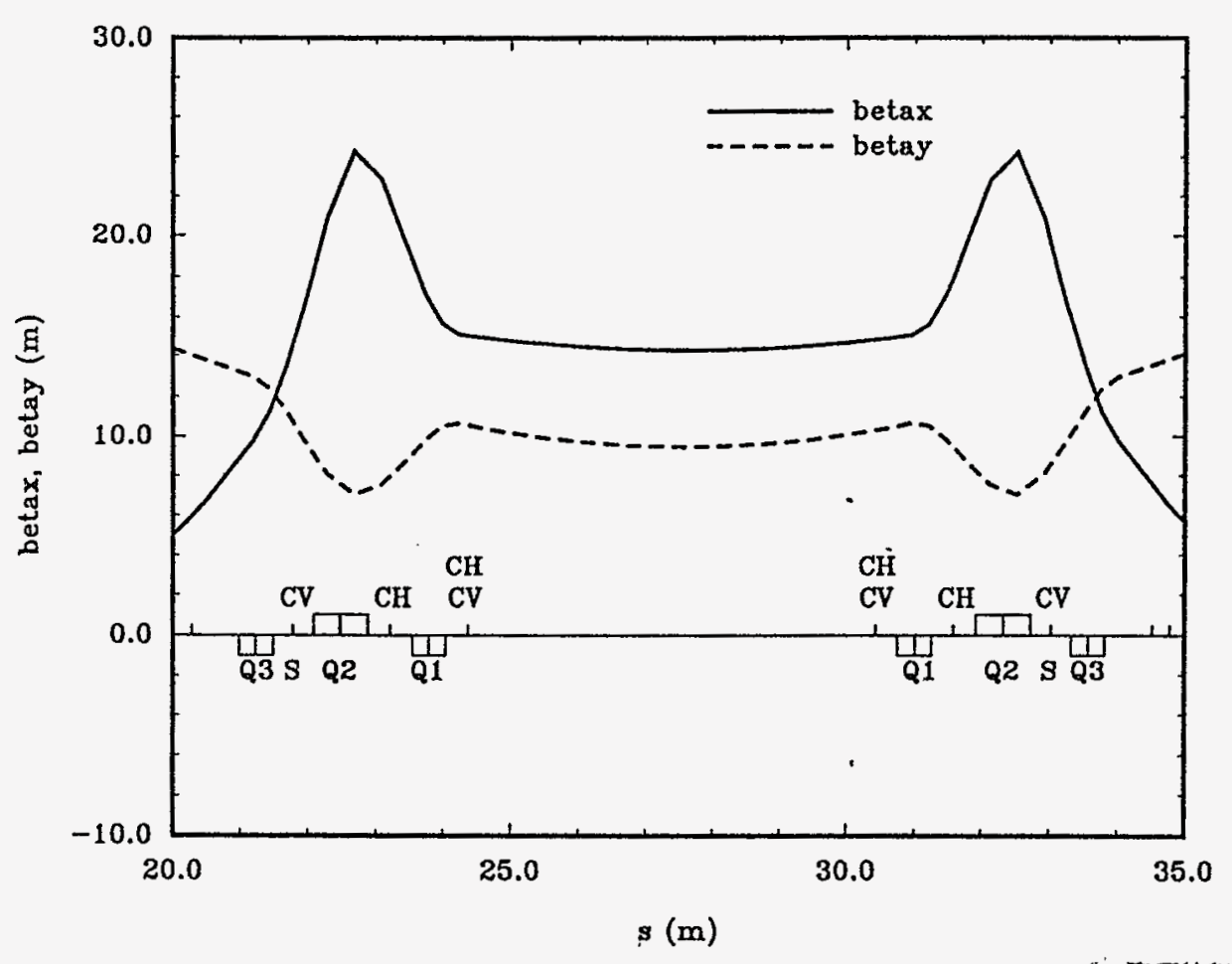

Figure 2: Local correction at a bending magnet section.

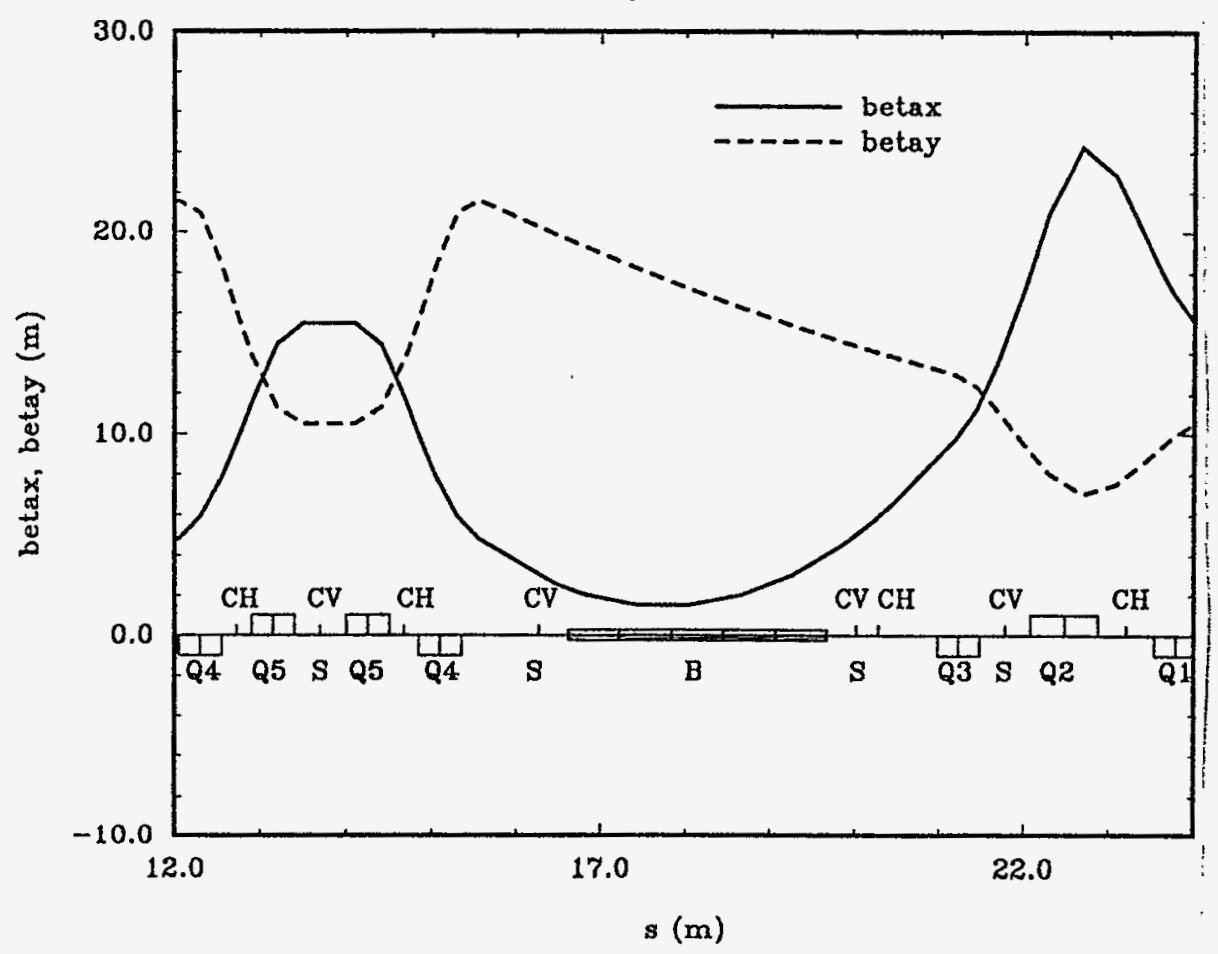


Table 4: Power supplies at $25 \mathrm{~Hz}$

\begin{tabular}{|l|c|c|c|c|}
\hline Magnet & $\begin{array}{c}\text { Horizontal } \\
\text { Correction }\end{array}$ & $\begin{array}{c}\text { Sextupole } \\
\text { Dipole Coils }\end{array}$ & $\begin{array}{c}\text { Horizontal in } \\
\mathrm{H} / \mathrm{V} \text { Combination }\end{array}$ & $\begin{array}{c}\text { Vertical in } \\
\mathrm{H} / \mathrm{V} \text { Combination }\end{array}$ \\
\hline Orbit motion $(\mu \mathrm{m})$ at $25 \mathrm{~Hz}$ & 100 & 100 & 100 & 100 \\
\hline $\begin{array}{l}\text { Corrector effective } \\
\text { strength }(\mu \mathrm{rad}) \text { at } 25 \mathrm{~Hz}\end{array}$ & 90 & 62 & 100 & 38 \\
\hline $\begin{array}{l}\text { Vacuum chamber } \\
\text { attenuation at } 25 \mathrm{~Hz}\end{array}$ & 0.15 & 0.60 & & \\
\hline $\begin{array}{l}\text { Corrector actual } \\
\text { strength }(\mu \mathrm{rad}) \text { at } 25 \mathrm{~Hz}\end{array}$ & 600 & 104 & & \\
\hline Corrector current $(\mathrm{A})$ at $25 \mathrm{~Hz}$ & 42 & 9.8 & & 0.57 \\
\hline Magnet impedance $(\Omega)$ at $25 \mathrm{~Hz}$ & 2.05 & 1.54 & & \\
\hline $\begin{array}{l}\text { Required Power supply } \\
\text { voltage }(\mathrm{V}) \text { at } 25 \mathrm{~Hz}\end{array}$ & 86 & 15 & 30.6 & 25.2 \\
\hline $\begin{array}{l}\text { Power supply } \\
\text { voltage specification }(\mathrm{V}) \\
\text { with } 90 \% \text { duty cycle }\end{array}$ & 23.4 & 41.4 & & \\
\hline
\end{tabular}

\section{Determination of Required Dynamic Range of Local Corrector Magnet Power Supplies}

In the previous section, the range for local correction at DC and AC was established. The requirements for the corrector power supplies are examined in this section. The power supply voltage is determined by the orbit correction capability at the upper end of the frequency range, which is set at $25 \mathrm{~Hz}$.

Table 4 lists various power supply parameters for a $100-\mu \mathrm{m}$ orbit correction at $25 \mathrm{~Hz}$. The progression of the rows is as follows. The necessary beam deflection angles produced by correctors are related to the desired orbit correction by the $4 \times 2$ bump matrices as determined by the lattice optics. (These matrices are displayed in the next section.) The largest deflection angle for each corrector type is listed in the second row of the table.

Then the attenuation due to eddy current losses in the vacuum chamber at $25 \mathrm{~Hz}$ is repeated from an earlier table. This, in effect, increases the power supply current for a desired angular deflection. This is more pronounced for horizontal correction (vertical magnetic fields) than for vertical correction mainly because the vacuum chamber is thinner at the vertical correctors. Row 4 shows the required corrector strength in terms of deflection angle. In row 5 , this deflection angle is converted to a magnet current using data from Table 1.

Next the impedance of the magnets at $25 \mathrm{~Hz}$ is displayed. The inductance of the magnets causes the power supply voltage for a given current to increase roughly in proportion to the operating frequency. This effect on the voltage is larger for the stand-alone horizontal corrector. The power supply voltage is simply the product of the magnet current and impedance. The power supply voltage required for a $100-\mu \mathrm{m}$ orbit correction at $25 \mathrm{~Hz}$ is listed in the second to last row of the table. The voltage specification of the power supplies from Table 1 is repeated here at the bottom 
of the table. The required power supply voltage for the stand-alone horizontal corrector exceeds the specification with $90 \%$ duty cycle. The required power supply voltage for the other magnets are within specification.

The impedance at $25 \mathrm{~Hz}$ for the horizontal corrector in Table 4 is pessimistic because the magnet impedance calculations reported in the Design Handbook don't take into account the eddy currents in the vacuum chamber. In general, the vacuum chamber eddy currents cause the circuit inductance to decrease with frequency, and the real part of the impedance to increase with frequency. A computer simulation that includes the effects of eddy-currents was done for the horizontal corrector with a vacuum chamber of wall thickness 0.10 " instead of the regular 0.50 ". Using the calculated magnet-vacuum chamber system inductance and the vacuum chamber attenuation factor for the magnetic field on axis, the required power supply voltage is found to be $28 \mathrm{~V}$. The reduction from the value of $86 \mathrm{~V}$ in Table 4 is due to the combination of including the eddy currents and using a much thinner vacuum chamber wall. Practically speaking, the 0.1 " thick vacuum chamber wall is machined from the 0.5 " thick wall while leaving 0.50 " high "ribs" for support. For this case the eddy currents are not easy to simulate, but the required power supply voltage will be greater than $28 \mathrm{~V}$.

\section{Power Supply Resolution Determination}

The required resolution for the local corrector magnet power supplies is estimated. We want the resolution of the local correction system to be such that the beam motion will be easily controlled to within $10 \%$ of the emittance, therefore $1 \%$ of the emittance is taken as the lowest order bit change of the programming voltage.

The resolution is determined by the operation of the correctors at DC. At higher frequencies, the effective resolution is improved because of the attenuation of the magnetic fields by the eddy currents in the vacuum chamber.

The corrector strengths for a local orbit distortion (also called a bump) are related to the desired orbit change by a $4 \times 2$ matrix. The matrix elements may change by a few percent depending on the final position of the correctors. Because of a constraint of the beam optics computer program used, the vertical dipole trims of the sextupoles are modeled as a stand-alone vertical corrector adjacent to the sextupoles.

For the undulator straight section, the necessary corrector strengths that produce a horizontal orbit change $\Delta x$ and $\Delta x^{\prime}$ are given by

$$
\left(\begin{array}{l}
k_{1} \\
k_{2} \\
k_{3} \\
k_{4}
\end{array}\right)=\left(\begin{array}{rr}
0.898 \mathrm{~m}^{-1} & -2.815 \\
-1.018 \mathrm{~m}^{-1} & 4.191 \\
-1.018 \mathrm{~m}^{-1} & -4.191 \\
0.898 \mathrm{~m}^{-1} & 2.815
\end{array}\right)\left(\begin{array}{c}
\Delta x \\
\Delta x^{\prime}
\end{array}\right)
$$

where the $k$ values are the kick angles of the correctors taken in sequence along the ring segment.

For the vertical direction,

$$
\left(\begin{array}{l}
k_{1} \\
k_{2} \\
k_{3} \\
k_{4}
\end{array}\right)=\left(\begin{array}{rr}
0.379 \mathrm{~m}^{-1} & -1.132 \\
-0.300 \mathrm{~m}^{-1} & 1.896 \\
-0.300 \mathrm{~m}^{-1} & -1.896 \\
0.379 \mathrm{~m}^{-1} & 1.132
\end{array}\right)\left(\begin{array}{c}
\Delta y \\
\Delta y^{\prime}
\end{array}\right)
$$


Using $10 \%$ of the values in equation (1) as $1 \%$ of the emittance, the required resolution for the horizontal plane is

$$
\begin{aligned}
\Delta k_{1,4} & =0.1 \mathrm{~min}\left(0.9 \Delta \sigma_{x}, 2.8 \Delta \sigma_{x^{\prime}}\right) \\
& =0.1 \mathrm{~min}(14 \mu \mathrm{rad}, 3 \mu \mathrm{rad}) \\
& =0.3 \mu \mathrm{rad} \\
\Delta k_{2,3} & =0.1 \mathrm{~min}\left(1.0 \Delta \sigma_{x}, 4.2 \Delta \sigma_{x^{\prime}}\right) \\
& =0.1 \mathrm{~min}(16 \mu \mathrm{rad}, 5 \mu \mathrm{rad}) \\
& =0.5 \mu \mathrm{rad}
\end{aligned}
$$

We take the resolution for the horizontal plane to be $.3 \mu \mathrm{rad}$. For the vertical plane, the required resolution is

$$
\begin{aligned}
\Delta k_{1,4} & =0.1 \mathrm{~min}\left(0.3 \Delta \sigma_{y}, 1.0 \Delta \dot{\sigma}_{y^{\prime}}\right) \\
& =0.1 \mathrm{~min}(1.3 \mu \mathrm{rad}, .5 \mu \mathrm{rad}) \\
& =.05 \mu \mathrm{rad} \\
\Delta k_{2,3} & =0.1 \mathrm{~min}\left(0.3 \Delta \sigma_{y}, 1.8 \Delta \sigma_{y^{\prime}}\right) \\
& =0.1 \mathrm{~min}(1.3 \mu \mathrm{rad}, 0.8 \mu \mathrm{rad}) \\
& =.08 \mu \mathrm{rad}
\end{aligned}
$$

We take the resolution for the horizontal plane to be $.05 \mu \mathrm{rad}$.

The above is repeated for the corrector magnet set for the bending magnet source. The local bump matrices are:

$$
\left(\begin{array}{l}
k_{1} \\
k_{2} \\
k_{3} \\
k_{4}
\end{array}\right)=\left(\begin{array}{rr}
0.780 \mathrm{~m}^{-1} & -2.651 \\
-0.529 \mathrm{~m}^{-1} & 2.650 \\
-0.410 \mathrm{~m}^{-1} & -1.915 \\
0.417 \mathrm{~m}^{-1} & 0.929
\end{array}\right)\left(\begin{array}{c}
\Delta x \\
\Delta x^{\prime}
\end{array}\right)
$$

for the horizontal set and

$$
\left(\begin{array}{l}
k_{1} \\
k_{2} \\
k_{3} \\
k_{4}
\end{array}\right)=\left(\begin{array}{rr}
0.432 \mathrm{~m}^{-1} & -0.728 \\
-0.268 \mathrm{~m}^{-1} & 1.451 \\
-0.541 \mathrm{~m}^{-1} & -2.124 \\
0.633 \mathrm{~m}^{-1} & 1.313
\end{array}\right)\left(\begin{array}{c}
\Delta y \\
\Delta y^{\prime}
\end{array}\right)
$$

for the vertical set. The matrix elements are of the same order of magnitude, therefore the resolution for undulator local correctors also applies to these.

Table 5 lists the necessary resolutions for the local correctors at DC. If full scale DC steering is taken to be $1.2 \mathrm{mrad}, 13$ bits and 16 bits are required for the horizontal and vertical corrector power supplies, respectively.

\section{Conclusion}

Since the required range of the local horizontal corrector power supplies exceed the specification in the present design, we suggest the following choice of possible action items: 
Table 5: Local corrector required resolutions

\begin{tabular}{|l|c|c|}
\hline & $\begin{array}{c}\text { Horizontal } \\
\mu \mathrm{rad}\end{array}$ & $\begin{array}{c}\text { Vertical } \\
\mu \mathrm{rad}\end{array}$ \\
\hline Undulator & 0.3 & 0.05 \\
\hline Bending magnet & 0.3 & 0.05 \\
\hline
\end{tabular}

- Remove material from the vacuum chamber to reduce the magnetic field attenuation. This will decrease the required power supply $\mathrm{AC}$ current.

- Increase the power supply voltage limit.

- Redesign the horizontal corrector magnet to reduce the resistance and inductance.

\section{DISCLAIMER}

This report was prepared as an account of work sponsored by an agency of the United States Government. Neither the United States Government nor any agency thereof, nor any of their employees, makes any warranty, express or implied, or assumes any legal liability or responsibility for the accuracy, completeness, or usefulness of any information, apparatus, product, or process disclosed, or represents that its use would not infringe privately owned rights. Reference herein to any specific commercial product, process, or service by trade name, trademark, manufacturer, or otherwise does not necessarily constitute or imply its endorsement, recommendation, or favoring by the United States Government or any agency thereof. The views and opinions of authors expressed herein do not necessarily state or reflect those of the United States Government or any agency thereof.

\section{DISTRIBUTION OF THIS DOCUMENT IS UNLWTIED}

